\title{
Penurunan Logam Timbal (Pb) pada Limbah Cair TPA Piyungan Yogyakarta dengan Constructed Wetlands Menggunakan Tumbuhan Eceng Gondok (Eichornia Crassipes)
}

\author{
Eko Siswoyo $^{1}$, Kasam ${ }^{1}$, dan L.M. Subhan Abdullah ${ }^{2}$ \\ ${ }^{1}$ Staf Pengajar, Jurusan Teknik Lingkungan, \\ Fakultas Teknik Sipil dan Perencanaan, Universitas Islam Indonesia, Yogyakarta \\ ${ }^{2}$ Alumnus Jurusan Teknik Lingkungan, \\ Fakultas Teknik Sipil dan Perencanaan, Universitas Islam Indonesia, Yogyakarta \\ email:eko_siswoyo@ftsp.uii.ac.id
}

\begin{abstract}
Abstrak
Salah satu permasalahan lingkungan yang ditimbulkan dari adanya lindi di TPA Piyungan yaitu pencemaran pada badan air, sungai dan air tanah. Untuk mengatasi permasalahan ini salah satunya dengan sistem Constructed Wetlands dengan menggunakan tumbuhah eceng gondok. Tujuan dari penelitian ini adalah untuk mengetahui tingkat penurunan konsentrasi Timbal $(\mathrm{Pb}$ ) yang terdapat dalam limbah cair TPA Piyungan dengan Constructed Wetlands menggunakan tumbuhan eceng gondok dan untuk mengetahui seberapa besar kapasitas serapan tumbuhan eceng gondok terhadap kandungan Timbal $(\mathrm{Pb})$ dalam limbah cair TPA Piyungan.

Dalam penelitian ini digunakan reaktor yang terbuat dari kayu yang dilapisi plastik dengan ukuran 0,5 $\mathrm{m}$ $x$ 1,0 m. Setiap reaktor diberi media tanah $5 \mathrm{~cm}$, dan diberi tumbuhan sebanyak 14 buah. Reaktor tersebut diberi perlakuan dengan konsentrasi limbah yang bervariasi (100\%, 75\%, 50\%, 25\%, dan 0\%), dan waktu pengambilan sampel (0, 3, 6, 9, 12 hari). Dengan menggunakan metode SSA (Spektrofotometri Serapan Atom)

Berdasarkan pengujian diperoleh bahwa penurunan logam Pb pada limbah cair TPA Piyungan hari ke12, yaitu sebesar $0.0501 \mathrm{mg} / \mathrm{L}$ pada konsentrasi $100 \%$, 0.0295mg/L pada konsentrasi $75 \%$, $0.0267 \mathrm{mg} / \mathrm{L}$ pada konsentrasi $50 \%$ dan $0.0041 \mathrm{mg} / \mathrm{L}$ pada konsentrasi $25 \%$.
\end{abstract}

Kata kunci: constructed wetlands, eceng gondok, lindi, 73imbale (Pb),

\section{Pendahuluan}

Timbulan sampah di TPA Piyungan menghasilkan leachate (lindi), lindi ini tidak bisa langsung dibuang ke lingkungan karena dapat menyebabkan pencemaran. Air limbah tersebut harus diolah terlebih dahulu agar mempunyai kualitas yang sama dengan kualitas air lingkungan yang tidak bersifat toksik bagi organisme maupun bagi manusia yang memanfaatkannya. Secara umum sistem pengolahan limbah cair dikategorikan kedalam tiga sistem pengolahan yaitu secara fisik, kimia, dan biologi.

Constructed Wetlands merupakan salah satu alternatif pengolahan air buangan sebelum dibuang kebadan air penerima. Pengolahan limbah dengan Constructed Wetlands memanfaatkan mikroorganisme dalam tanah dan tanaman dalam areal tersebut. Dalam sistem ini terjadi aktivitas pengolahan seperti sedimentasi, filtrasi, gas transfer, adsorbsi, pengolahan kimia dan pegolahan biologis karena aktivitas mikrorganisme dalam tanah dan aktivitas tanaman untuk proses fotosintesis, pengoksida dan plan uptake (Metcalf \& Eddy, 1990). Keuntungan pengolahan dengan 
sistem constructed wetlands adalah biaya pengolahan dan perawatan lebih murah, mampu mengolah air limbah domestik dan industri dimana kualitas effluent yang dihasilkan terbukti baik dan sistem manajemen dan kontrol yang mudah. Sistem Constructed wetlands dikonstruksi sedemikian rupa dan diisi dengan batuan, tanah dan zat organik untuk mendukung tumbuhan seperti eichornia, reeds, cattail.

Tumbuhan ini mempunyai daya regenerasi yang cepat karena potongan-potongan vegetatifnya yang terbawa arus akan terus berkembang menjadi eceng gondok dewasa. Eceng gondok sangat peka terhadap keadaan yang unsur haranya didalam air kurang mencukupi, tetapi responnya terhadap kadar unsur hara yang tinggi juga besar. Proses regenerasi yang cepat dan toleransinya terhadap lingkungan yang cukup besar, menyebabkan eceng gondok dapat dimanfaatkan sebagai pengendali pencemaran lingkungan (Soerjani, 1975). Tumbuhan eceng gondok mampu menyerap logam berat di perairan dan sekaligus bisa menjadi biomonitor merkuri di perairan, sehingga tumbuhan ini dapat berperan penting dalam pengelolaan lingkungan seperti pencemaran oleh merkuri (Maheswar, et al., 1990).

Timbal atau dalam keseharian lebih dikenal dengan timah hitam dan dalam bahasa ilmiahnya dinamakan Plumbum. Logam ini termasuk kedalam kelompok logam-logam golongan IV-A pada tabel periodik. Timbal mempunyai nomor atom (NA) 82 dengan bobot atau berat atom (BA) 207,2 (Palar, 1994). Penyebaran logam Timbal di bumi sangat sedikit, jumlah timbal yang terdapat di seluruh lapisan bumi hanyalah 0,0002 \% dari jumlah kerk bumi. Logam Pb merupakan logam lunak berwarna abu-abu atau putih kebiruan seperti perak, sangat berkilat jika baru dipotong dan jika kena udara akan menjadi kusam.

Toksisitas adalah kemampuan suatu molekul suatu bahan kimia atau senyawa kimia untuk menimbulkan kerusakan pada saat mengenai bagian permukaan tubuh atau bagian dalam tubuh yang peka. Unsur $\mathrm{Pb}$ yang masuk ke dalam lingkungan tidak langsung membahayakan kehidupan mahkluk hidup, logam tersebut membahayakan metabolisme mahkluk jika berada dalam batas melebihi ambangnya. Unsur $\mathrm{Pb}$ merupakan unsur logam yang sangat toksik pada tanaman. Unsur $\mathrm{Pb}$ dapat dimanfaatkan sebagai pelapis keramik (glaze), pelapis pita, kabel, film, batrai, pelapis pipa dan solder. Unsur $\mathrm{Pb}$ resistan terhadap bahan korosit, selain itu $\mathrm{Pb}$ digunakan sebagai campuran pewarna, dikarenakan $\mathrm{Pb}$ mempunyai berbagai warna, dan bersifat sebagai pelindung serta mempunyai nilai kelarutan yang kecil di dalam air.

Dalam penelitian ini akan dikaji kemampuan tanaman eceng gondok dalam mengabsorpsi logam Timbal (Pb). Parameter yang mempengaruhi kemampuan absorpsi tanaman eceng gondok yaitu konsentrasi logam, pH dan pola tanam terhadap tanaman eceng gondok yang akan diteliti. Dengan 
mengacu pada penelitian terdahulu maka penelitian ini akan mengetahui seberapa besar kapasitas serapan yang dilakukan oleh tanaman eceng gondok (Eichornia Crassipes) terhadap kandungan $\mathrm{Pb}$ dalam limbah cair TPA Piyungan dan untuk mengetahui apakah limbah cair TPA Piyungan tersebut akan mempengaruhi pertumbuhan dari tanaman eceng gondok.

\section{Metodologi Penelitian}

Penelitian ini merupakan penelitian dengan skala laboratorium yang dilakukan di Jurusan Teknik Lingkungan Universitas Islam Indonesia Yogyakarta. Variabel yang digunakan dalam penelitian ini adalah variabel bebas (independent variable) yaitu jenis tumbuhan yang digunakan berupa tumbuhan Eceng Gondok yang mempunyai panjang akar, jumlah daun dan lebar daun yang sama. Variabel terikat (dependent variable) dalam penelitian ini adalah kandungan logam timbal. Variasi yang digunakan adalah variasi konsentrasi limbah cair TPA Piyungan, yang akan dijadikan obyek penelitian dan analisa yaitu 0\%, 25\%, 50\%, 75\% dan 100\% tanpa tumbuhan yang digunakan sebagai kontrol serta 0\%, 25\%, 50\%, 75\%, dan 100\% ditanami eceng gondok. Variasi konsentrasi air limbah dilakukan dengan pengenceran yang menggunakan air sumur. Pengaliran limbah cair pada reaktor dilakukan selama 12 hari, kemudian dilakukan analisa di laboratorium pada variasi waktu ke 0, 3, 6, 9, dan 12 hari.

Media tanam berupa reaktor terbuat dari kayu dan dilapisi plastik sebagai lapisan kedap air. Reaktor yang digunakan dalam penelitian ini berjumlah 10 buah reaktor. Tiap reaktor akan diberi perlakuan konsentrasi limbah yang berbeda. Reaktor diatas terbagi atas reaktor kontrol, dimana reaktor ini diberi limbah namun tidak ditanami eceng gondok dan reaktor uji yang mana reaktor diberi limbah dan ditanami eceng gondok Media tanaman yang digunakan adalah tanah dengan ketinggian masing-masing $5 \mathrm{~cm}$ untuk tiap reaktor dan dilakukan di dalam rumah kaca.

\section{Hasil dan Pembahasan}

Pengujian awal dilakukan terhadap lindi TPA Piyungan dan diperoleh konsentrasi Pb dalam lindi sebesar 0,3211 ppm. Dari hasil tersebut menunjukkan bahwa kualitas air buangan TPA Piyungan untuk parameter timbal belum memenuhi syarat untuk dapat dibuang ke badan air, karena masih jauh berada diatas 0,03 mg/L yang merupakan ambang batas dari Baku Mutu Limbah Cair berdasarkan PP No. 82 th. 2001.

Tumbuhan eceng gondok diambil dari daerah Maguwo Sleman dengan jumlah masing-masing reaktor sebanyak 14 buah eceng gondok yang berat panjang serta ukurannya di perkirakan sama, ini 
di karenakan agar dalam proses penyerapan tanaman bisa mempunyai kemampuan yang sama. Tumbuhan eceng gondok tersebut dibiarkan beradaptasi dengan lingkungannya selama 3 hari. Konsentrasi awal timbal $(\mathrm{Pb})$ setelah diencerkan dapat dilihat pada Tabel 1.

Tabel 1. Hasil Pengujian Awal Konsentrasi Timbal $(\mathrm{Pb})$ dalam lindi

\begin{tabular}{|c|c|c|c|}
\hline No. & Sample & Konsentrasi $\mathrm{Pb}(\mathrm{mg} / \mathrm{L})$ & Metode \\
\hline 1 & $0 \%$ & 0.0062 & AAS \\
2 & $25 \%$ & 0.0425 & AAS \\
3 & $50 \%$ & 0.0741 & AAS \\
4 & $75 \%$ & 0.1560 & AAS \\
5 & $100 \%$ & 0.3211 & AAS \\
\hline
\end{tabular}

Penelitian ini dilakukan selama 12 hari dimana pengamatan dilakukan setiap hari, akan tetapi untuk pengambilan sampelnya dilakukan selang 3 hari, ini bertujuan untuk bisa lebih mengetahui perbandingan penurunan yang lebih baik Adapun konsentrasi limbah yang berbeda-beda yaitu konsentrasi limbah 0\%, 25\%, 50\%, 75\% dan 100\%. Untuk mengetahui konsentrasi timbal pada air limbah TPA Piyungan dengan eceng gondok (reaktor uji) maupun tanpa eceng gondok (reaktor kontrol) dapat dilihat pada Gambar 1 dan 2.

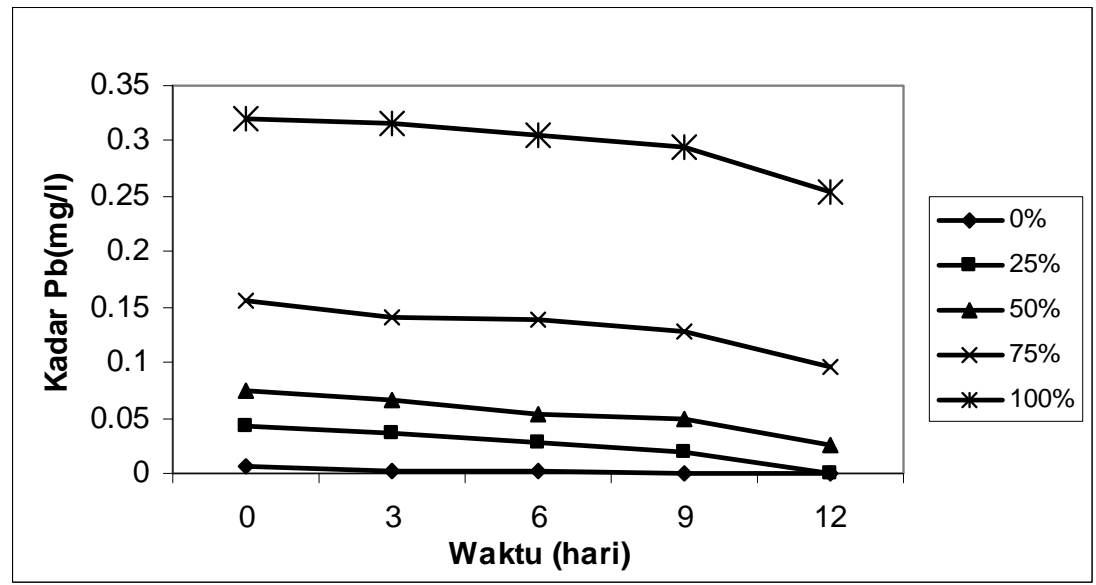

Gambar 1. Konsentrasi Pb dari hari ke-3 sd hari ke-12 pada Reaktor Kontrol

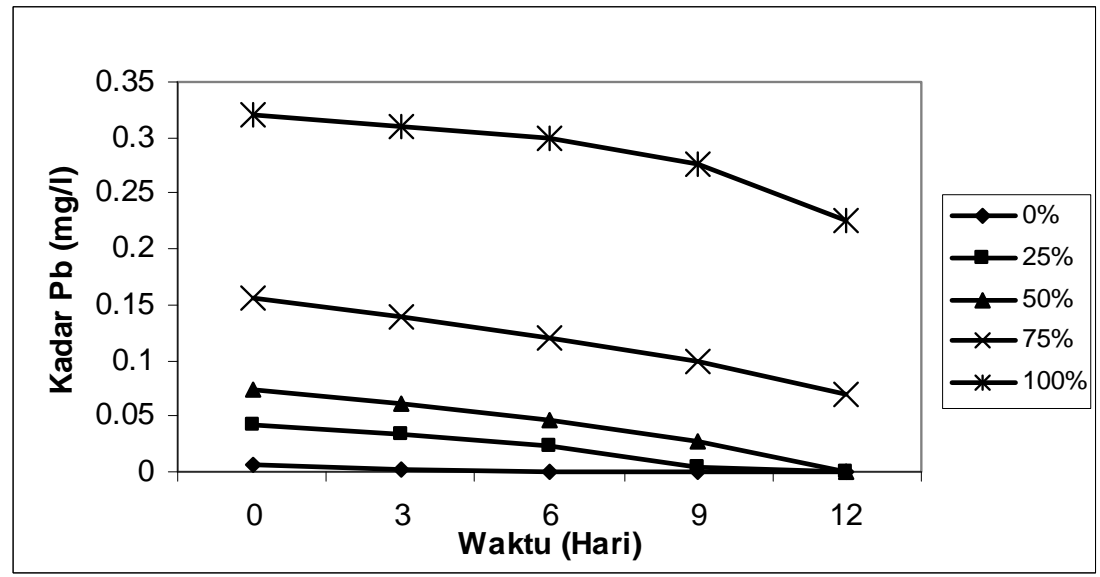

Gambar 2. Konsentrasi Pb dari hari ke-3 sd hari ke-12 pada Reaktor Uji 
Tabel 2. Hasil Pengujian Konsentrasi Awal Pb Pada Tumbuhan Eceng Gondok

\begin{tabular}{|c|c|c|c|}
\hline No. & Sample & Konsentrasi $\mathrm{Pb}(\mathrm{mg} / \mathrm{L})$ & Metode \\
\hline 1 & Akar & 0.0362 & AAS \\
2 & Daun & 0.0015 & AAS \\
\hline
\end{tabular}

Tabel 3. Tingkat Penurunan Logam Pb Pada Reaktor Uji

\begin{tabular}{|c|c|c|c|c|c|}
\hline \multirow{2}{*}{ Konsentrasi Limbah } & \multicolumn{5}{|c|}{ Penurunan Kandungan Pb (mg/L) } \\
\cline { 2 - 5 } & hari ke-0 & hari ke-3 & hari ke-6 & hari ke-9 & hari ke-12 \\
\hline $0 \%$ & 0 & 0.0048 & 0.0013 & 0.0000 & 0.0000 \\
$25 \%$ & 0 & 0.0085 & 0.0116 & 0.0181 & 0.0041 \\
$50 \%$ & 0 & 0.0125 & 0.0143 & 0.0205 & 0.0267 \\
$75 \%$ & 0 & 0.0166 & 0.0190 & 0.0218 & 0.0295 \\
$100 \%$ & 0 & 0.0110 & 0.0116 & 0.0226 & 0.0501 \\
\hline
\end{tabular}

Dari Gambar 1 dan 2 terlihat perbedaan penurunan Pb dari hari ke-0 sampai hari ke-12. Proses penurunan konsentrasi $\mathrm{Pb}$ terjadi karena proses penyerapan dan absorbsi oleh eceng gondok, dan juga terjadi karena proses pengendapan. Hal ini dapat dilihat pada reaktor yang tidak ditanami tumbuhan eceng gondok (kontrol) juga terjadi penurunan kadar $\mathrm{Pb}$, karena selama penelitian reaktor didiamkan, sehingga dapat diketahui bahwa dalam hal ini telah terjadi proses pengendapan $\mathrm{Pb}$ secara alamiah. Pengukuran kadar $\mathrm{Pb}$ yang terdapat dalam tumbuhan uji diperlukan untuk mengetahui seberapa besar tumbuhan uji tersebut mampu menyerap $\mathrm{Pb}$ yang terdapat dalam lindi TPA Piyungan seperti yang terlihat pada Tabel 2.

Setelah mengetahui konsentrasi total Logam $\mathrm{Pb}$ pada tumbuhan eceng gondok, maka dapat pula diketahui tingkat penurunan Logam $\mathrm{Pb}$ pada reaktor yang ditanami eceng gondok tersebut seperti pada Tabel 3.

Tabel 3 menunjukkan bahwa tumbuhan eceng gondok mampu menurunkan logam $\mathrm{Pb}$ maksimal $0.0501 \mathrm{mg} / \mathrm{L}$ pada konsentrasi limbah 100\% pada hari ke-12 dimana ingkat penurunan pada reaktor uji berbeda-beda. Pada hari ke-3 tumbuhan eceng gondok mampu menurunkan limbah untuk konsentrasi $0 \%$ sebesar $0.0048 \mathrm{mg} / \mathrm{L}$, pada konsentrasi limbah $25 \%$ sebesar $0.0085 \mathrm{mg} / \mathrm{L}$, pada konsentrasi limbah 50\% sebesar $0.0125 \mathrm{mg} / \mathrm{L}$ pada konsentrasi limbah 75\% dan sebesar 0.0166 mg/L dan pada konsentrasi limbah 100\% sebesar 0.0110 mg/L.

Tabel 4. Effisiensi Penurunan Logam Timbal (Pb) Pada Reaktor Kontrol

\begin{tabular}{|c|c|c|c|c|c|}
\hline \multirow{2}{*}{ Hari ke } & \multicolumn{5}{|c|}{ Konsentrasi } \\
\cline { 2 - 6 } & $0 \%$ & $25 \%$ & $50 \%$ & $75 \%$ & $100 \%$ \\
\hline 0 & 0 & 0 & 0 & 0 & 0 \\
\hline 3 & 75.97 & 14.16 & 11.74 & 9.48 & 1.9 \\
\hline 6 & 78.23 & 33.62 & 28.23 & 11.63 & 5.17 \\
\hline 9 & 100 & 54.71 & 34.79 & 18.05 & 8.26 \\
\hline 12 & 100 & 100 & 65.61 & 38.6 & 20.63 \\
\hline
\end{tabular}


Tabel 5. Efisiensi Penurunan Logam Pb pada Reaktor Uji

\begin{tabular}{|c|c|c|c|c|c|}
\hline \multirow{2}{*}{ Hari ke- } & \multicolumn{5}{|c|}{ Tingkat penurunan Pb pada setiap variasi konsentras lindi (\%) } \\
\cline { 2 - 6 } & $0 \%$ & $25 \%$ & $50 \%$ & $75 \%$ & $100 \%$ \\
\hline 0 & 0 & 0 & 0 & 0 & 0 \\
\hline 3 & 77.96 & 20 & 16.87 & 10.68 & 3.43 \\
\hline 6 & 100 & 47.45 & 36.21 & 22.86 & 7.06 \\
\hline 9 & 100 & 90.2 & 63.88 & 36.86 & 14.12 \\
\hline 12 & 100 & 100 & 100 & 55.77 & 29.74 \\
\hline
\end{tabular}
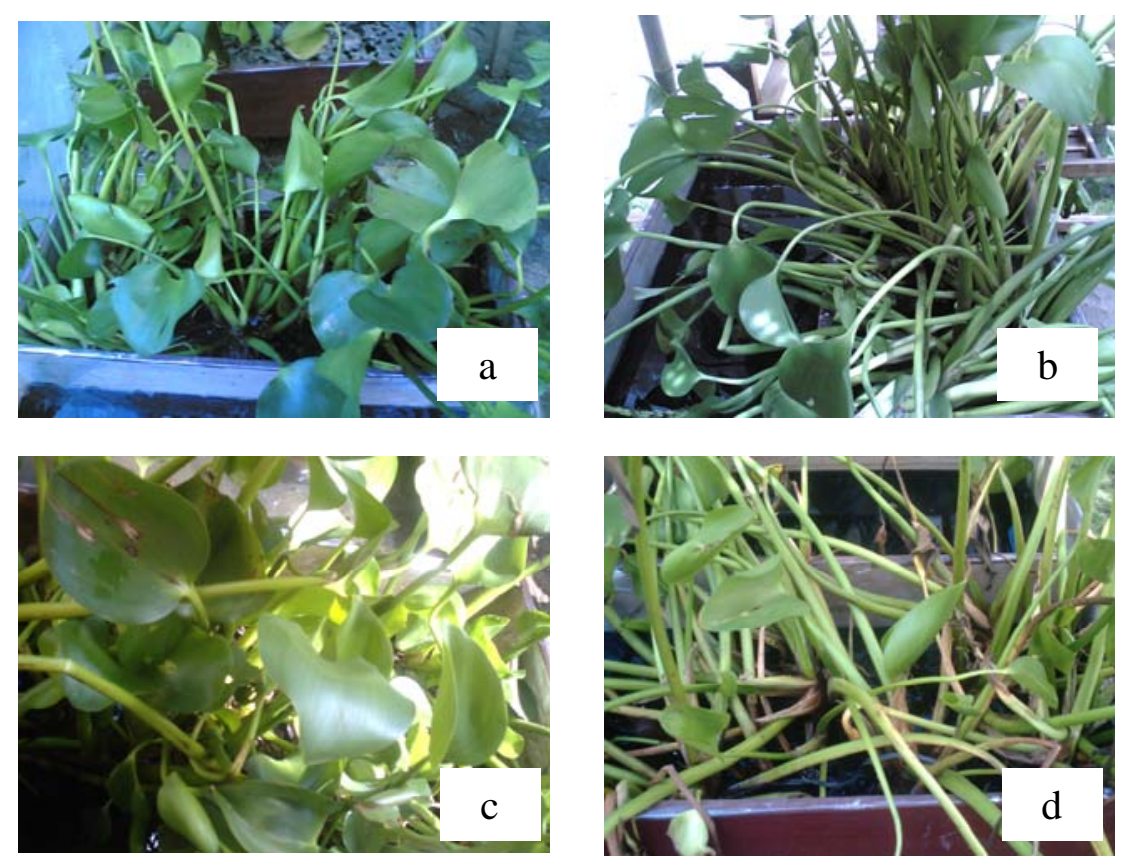

Gambar 3. Tumbuhan eceng gondok sebelum dan sesudah pengolahan hari ke-12 (a dan c reaktor kontrol, b dan d reaktor 100\%).

Setelah diketahui tingkat penurunan logam timbal $(\mathrm{Pb})$ pada Limbah Cair TPA Piyungan pada reaktor uji dan kontrol maka dapat dicari effisiensi penurunannya seperti yang terlihat pada Tabel 4 dan Tabel 5.

Dari Tabel 5 dapat dilihat bahwa effisiensi penurunan logam Timbal oleh tumbuhan eceng gondok pada hari ke-9 terbesar adalah pada konsentrasi 25\%. Kondisi tersebut menyebabkan keadaan eceng gondok menurun yang ditandai dengan perubahan warna daunnya dari hijau segar menjadi coklat kering.

Keberadaan $\mathrm{Pb}$ dan logam-logam lain yang terdapat dalam lindi TPA Piyungan memberikan pengaruh negatif terhadap pertumbuhan tumbuhan eceng gondok. Hal ini dapat dilihat dari kondisi tumbuhan uji sebelum pengolahan dan sesudah pengolahan, dimana dari Gambar 3 terlihat dengan jelas bahwa kondisi tumbuhan uji menjadi tidak sehat setelah 12 hari kontak dengan lindi. 
Selain konsentrasi logam berat yang ada pada lindi, keberadaan mineral lain juga berpengaruh terhadap tingkat penyerapan logam oleh tumbuhan air ini. Semakin sedikit mineral yang ada dalam air limbah, maka tingkat penyerapan logam tersebut semakin tinggi (Agneta G, et al., 2004). Hal ini akan meningkatkan kadar logam berat yang terakumulasi dalam tumbuhan uji.

\section{Kesimpulan}

Bedasarkan hasil penelitian yang dilakukan, diketahui bahwa tingkat penurunan logam $\mathrm{Pb}$ dari air limbah TPA Piyungan Yogyakarta dengan tumbuhan eceng gondok dipengaruhi oleh konsentrasi limbah TPA Piyungan dan waktu kontak. Penurunan logam Pb paling besar pada konsentrasi 100\% dan waktu kontak 12 hari, kapasitas serapan logam yang diperoleh sebesar $0.0501 \mathrm{mg} / \mathrm{L}$. Besarnya kemampuan penurunan Pb pada air limbah TPA Piyungan dengan tanaman eceng gondok dapat dijadikan suatu parameter bahwa tanaman eceng gondok dapat digunakan untuk menjadi salah satu fitoremediator dalam pengolahan air buangan.

\section{Daftar Pustaka}

Agneta G, et al. (2004). Accumulation of heavy metals in water spinach (Ipomea aquatic) cultivated in The Bangkok Region, Thailand, Journal of Environmental Toxicology and Chemistry, vol. 21, no. 9, p 1934-1939.

Maheswar L, et al. (1990). Studies on the ability of water hyacinth (Eichornia crassipes) to bioconcentrate and biomonitor aquatic mercury, Journal of Environmental Pollution, 66, page 89-99.

Met Calf, dan Eddy. (1990). Waste Water Engineering Treatment Disposal Reuse, New York, Mc Brow-Hill, Tenth Edition.

Palar. Drs. Heryando. (1994). Pencemaran dan toksikologi logam berat, Rineka Cipta, Jakarta.

Soerjani, S.W. (1975). Eceng Gondok Sebagai Penyerap Pencemar, SEAMEO, Biotrop, Bogor. 